\title{
ANALISIS KEBERLANJUTAN SUMBER DAYA IKAN KARANG FAMILI CAESIONIDAE DI KAWASAN KONSERVASI TAMAN NASIONAL KARIMUNJAWA
}

\author{
Ernik Yuliana \\ Nurhasanah \\ Idha Farida \\ FMIPA Universitas Terbuka \\ e-mail: ernik@ecampus.ut.ac.id
}

\begin{abstract}
Reef fish resources are the main catch in Karimunjawa National Park. The fishing activities are feared to have an impact on the sustainability of fish resources inside and outside the conservation area. The purpose of this study is to analyze of the sustainability of reef fish resources (Family Caesionidae) in marine protected area. The study was conducted in Karimunjawa National Park (TNKJ) in Jepara Regency, Central Java, April-September 2017. Data collection was carried out by survey, observation, and deep interview methods, including primary data. Coral fish of the Caesionidae family, which were the object of research, were Caesio cuning and Caesio caerulaurea. Data collection on fish length and weight was carried out six times sampling (for six months). Examples of fish taken from three collectors in Karimunjawa Village. Water quality data was taken for analysis of $\mathrm{pH}$, total dissolved solids (TDS), temperature, biochemical oxygen demand (BOD), chemical oxygen demand (COD), total suspended solids (TSS), and salinity. Data analysis using FISAT II program and estimation of spawning potential ratio (SPR) using length-based spawning potential ratio analysis. To analyze management aspects of reef fishes, stakeholder analysis was carried out. The research results indicated that Caesio cuning and Caesio caerulaurea had exploitation rate values of 0.69 and 0.61 , in the condition of over exploited. The spawning potential ratio (SPR) value are 0.14 and 0.25 (the capacity of adult fish that is ready naturally to spawn is very small). Water quality data is below the water quality standard for marine biota, indicated that the waters of the Karimunjawa National Park was sustainable. The results of stakeholder analysis indicated that there are four parties who are the subject of management. They were fisheries management authorities and NonGovernmental Organizations (NGOs) as work partners of the management authority.
\end{abstract}

Keywords: Caesionidae, reef fish, sustainability

\begin{abstract}
ABSTRAK
Ikan karang merupakan sumber daya ikan yang menjadi tangkapan utama nelayan di Taman Nasional Karimunjawa. Penangkapan ikan tersebut dikhawatirkan berdampak pada keberlanjutan sumber daya ikan di dalam dan luar kawasan konservasi. Tujuan studi ini adalah menganalisis keberlanjutan sumber daya ikan karang Famili Caesionidae di kawasan konservasi. Studi dilakukan di Taman Taman Nasional Karimunjawa (TNKJ) Kabupaten Jepara, Jawa Tengah, April-September 2017. Pengumpulan data dilakukan dengan metode survei, observasi, dan wawancara dengan mengumpulkan data primer. Ikan karang Famili Caesionidae yang menjadi objek penelitian adalah Caesio cuning dan Caesio
\end{abstract}


caerulaurea. Pengambilan data panjang dan bobot ikan dilakukan empat kali sampling (selama empat bulan). Contoh ikan diambil dari tiga pengepul di Desa Karimunjawa. Data kualitas air diambil untuk analisis $\mathrm{pH}$, total dissolved solids (TDS), suhu, biochemical oxygen demand (BOD), chemical oxygen demand (COD), total suspended solids (TSS), dan salinitas. Analisis data menggunakan program FISAT II dan pendugaan spawning potential ratio (SPR) menggunakan analisis length-based spawning potential ratio. Untuk menganalisis aspek pengelolaan, dilakukan analisis stakeholder. Hasil penelitian menunjukkan bahwa Caesio cuning dan Caesio caerulaurea mempunyai nilai laju eksploitasi berturut-turut 0,69 dan 0,61, berada pada kondisi over exploited. Nilai spawning potential ratio (SPR) berturut-turut adalah 0,14 dan 0,25 (kapasitas ikan dewasa yang siap memijah di alam sangat sedikit). Data kualitas air berada di bawah baku mutu perairan untuk biota laut, menunjukkan perairan TNKJ dalam kondisi berlanjut. Hasil analisis stakeholder menunjukkan ada empat pihak yang menjadi subjek pengelolaan, dan semuanya adalah pemegang otoritas pengelolaan perikanan dan Lembaga Swadaya Masyarakat (LSM) sebagai partner kerja otoritas pengelola.

Kata kunci: Caesionidae, ikan karang, keberlanjutan

Ikan karang merupakan target tangkapan utama di Taman Nasional Karimunjawa (TNKJ). Dari beberapa jenis ikan karang yang ditangkap oleh nelayan, famili Caesionidae merupakan hasil tangkapan utama, terutama jenis ikan ekor kuning (Caesio cuning), dengan proporsi 26,21\% dari seluruh hasil tangkapan, dan ikan pisang-pisang (Caesio caerulaurea) dengan proporsi 3,59\%. Selain ikan ekor kuning dan pisang-pisang, ikan karang lainnya yang banyak ditangkap oleh nelayan adalah kakap merah $(7,53 \%)$, betet/ijo $(4,11 \%)$, dan kerapu $(1,91 \%)$. Alat tangkap yang banyak digunakan adalah panah (speargun) disamping alat tangkap lainnya yaitu bubu dan pancing (Yuliana, Boer, Fahrudin, Kamal, Pardede, 2016; PPP Karimunjawa, 2014).

Balai Taman Nasional Karimunjawa (BTNKJ) telah menyediakan wilayah dengan luas $92,18 \%$ dari seluruh luas TNKJ, yaitu zona tradisional perikanan (BTNKJ, 2014). Dalam zona inilah, nelayan dapat menangkap ikan dengan alat tangkap tradisional dan kapal penangkap ikan < 5 GT. Tujuan penetapan alat tangkap dan armada tersebut adalah melindungi kelestarian sumber daya ikan (SDI) agar tidak mengalami eksploitasi berlebihan.

Tekanan penangkapan terhadap ikan karang menyebabkan ancaman terhadap kelestarian SDI, karena overfishing terjadi pada beberapa spesies ikan karang (Sadovy de Mitcheson et al., 2008). Terumbu karang juga terancam mengalami kerusakan akibat penangkapan ikan, terutama dengan adanya penggunaan alat tangkap yang merusak (destructive fishing) (Campbell, Kartawijaya, Yulianto, Prasetia, \& Clifton, 2013). Berdasarkan tekanan penangkapan dan ancaman degradasi terhadap terumbu karang, perlu dilakukan analisis keberlanjutan sumber daya ikan karang, termasuk di wilayah taman nasional Karimunjawa sebagai salah satu kawasan konservasi. Pengelolaan perikanan berkelanjutan memuat empat aspek (Charles, 2001), yaitu: 1) keberlanjutan ekologi, memelihara keberlanjutan stok atau biomassa sehingga tidak melewati daya dukung lingkungannya, serta meningkatkan kapasitas dan kualitas ekosistem; 2) keberlanjutan sosio-ekonomi, memperhatikan keberlanjutan kesejahteraan pelaku perikanan pada tingkat individu, mempertahankan dan mencapai kesejahteraan masyarakat yang lebih tinggi; 3) keberlanjutan komunitas, memperhatikan keberlanjutan kesejahteraan komunitas masyarakat dalam pembangunan perikanan; 4) keberlanjutan kelembagaan, terkait pemeliharaan aspek finansial dan administrasi yang 
sehat. Analisis keberlanjutan SDI perlu dilakukan terus-menerus karena sumber daya perikanan bersifat dinamik akibat perubahan mortalitas (Carruthers, Walters, \& McAllister, 2012).

Artikel ini memaparkan hasil penelitian tentang analisis keberlanjutan SDI karang di TNKJ. SDI karang yang menjadi objek penelitian adalah famili Caesionidae karena hasil tangkapan utama di TNKJ. Analisis keberlanjutan dilakukan terhadap indikator-indikator keberlanjutan SDI karang, yaitu laju eksploitasi, spawning potential ratio, dan kualitas air, serta analisis stakeholder untuk aspek pengelolaan.

\section{METODE}

Penelitian dilakukan di TNKJ Kabupaten Jepara, Provinsi Jawa Tengah, April-September 2017. Ikan karang contoh yang diambil dalam penelitian ini adalah ikan pisang-pisang (Caesio caerulaurea) dan ekor kuning (Caesio cuning), periode Juni-September 2017. Pengumpulan data menggunakan metode survei dan observasi. Data primer yang dikumpulkan adalah panjang dan bobot ikan, hasil tangkapan ikan karang, dan trip penangkapan. Contoh ikan diambil dari tiga pengepul di Desa Karimunjawa.

Lokasi pengambilan sampel air berada di lima lokasi berdasarkan pertimbangan kemerataan kondisi perairan (Tabel 1). Dari lima lokasi tersebut diharapkan dapat diambil kesimpulan tentang kualitas air di TNKJ.

Tabel 1. Lokasi Pengambilan Sampel Air

\begin{tabular}{cl}
\hline Lokasi & Deskripsi/Posisi Lokasi di Perairan TNKJ \\
\hline 1 & $100 \mathrm{~m}$ sebelah selatan Pulau menjangan Besar (daerah Ujung Gantungan) \\
2 & $50 \mathrm{~m}$ sebelah barat Pulau Menjangan Kecil \\
3 & $100 \mathrm{~m}$ sebelah barat Tanjung Gelam \\
4 & Sebelah barat Pulau Karimunjawa (daerah legon Buaya, Jatikerep) \\
5 & Pelabuhan H. Afif \\
\hline
\end{tabular}

Untuk menganalisis laju eksploitasi, digunakan rumus empiris Pauly (1984) dengan menggunakan data rata-rata suhu permukaan perairan tahunan $(\mathrm{T})$ dengan rumus sebagai berikut:

$$
M=\exp \left(-0,0152-0,279 \ln L_{\infty}+0,6543 \ln K+0,4634 \ln T\right)
$$

Pendugaan mortalitas alami (M) juga dapat dilakukan pada software FISAT II dengan metode Pauly's M Equation dan mortalitas total (Z) dengan metode Lenght converted-catch curve (Pauly 1984; Gayanilo, Sparre, \& Pauly, 2005; Ongkers, 2006). Setelah laju mortalitas total (Z) dan laju mortalitas alami (M) diketahui maka laju mortalitas penangkapan dapat ditentukan melalui hubungan:

$$
\mathrm{F}=\mathrm{Z}-\mathrm{M}
$$

Selanjutnya Pauly (1984) menyatakan laju eksploitasi dapat ditentukan dengan membandingkan $F$ dengan Z sebagai berikut:

$$
E=\frac{F}{Z}
$$

Spawning Potential Ratio (SPR) dianalisis menggunakan biomassa yang dihitung untuk setiap kelompok panjang dan "spawning stock biomass (SSB)": 


$$
S S B=\sum_{t=t_{m}}^{t_{\lambda}} N_{t} x W_{t}
$$

di mana $W_{t}$ adalah rata-rata "weight-at-age". SSB dihitung pada tingkat "pristine" $\left(\mathrm{B}_{0}\right)$. Lalu SPR dihitung untuk tingkat $L_{c}$ dan $F$ yang berbeda, dengan membagi SSB yang dieksploitasi dengan SSB "pristine"

$$
S P R=\frac{S S B_{F}}{S S B_{F=0}}
$$

Spawning potential ratio (SPR) atau rasio potensi pemijahan adalah jumlah telur yang dapat dihasilkan, rata-rata dalam suatu sediaan/stok induk ikan dibagi dengan jumlah yang dapat dihasilkan oleh rata-rata dalam sediaan stok induk yang tidak tertangkap (Blackhart, Stanton, \& Shimada, 2006). Nilai SPR hasil analisis berkisar antara 0-1 atau dalam presentase 0-100\%. Nilai SPR ikan sebelum ada kegiatan penangkapan mencapai $100 \%$ dari potensi alamiahnya, dan jika sudah ada penangkapan maka potensi reproduksi akan menurun. Berdasarkan klasifikasi Ault, Smith, Monaco, \& Appeldoom (2008) pada penelitian ikan karang di Puerto Rico, SPR standar atau SPR pada kondisi maximum sustainable yield (MSY) adalah 30\%. Artinya ikan dengan nilai SPR kurang dari $30 \%(0,3)$ terindikasi mengalami overfished.

Untuk menganalisis keterlibatan stakeholder dalam pengelolaan sumber daya ikan, dilakukan analisis stakeholder. Langkah-langkah analisis stakeholder menurut Grimble, Chan, Aglionby, \& Quan (1995) dan Bryson (2004) adalah: 1) Identifikasi pemangku kepentingan yang berperan dalam pemanfaatan sumber daya perikanan karang; 2) Menentukan kategori pemangku kepentingan dalam kelompok prioritas sebagai primary stakeholders, secondary stakeholders, dan external stakeholders; 3) Identifikasi kepentingan dan karakteristik setiap pemangku kepentingan; 4) Identifikasi pola dan konteks interaksi antar-pemangku kepentingan; 5) Menetapkan pilihan untuk pengelolaan.

Penentuan skor menggunakan skala Likert. Setelah penentuan skor setiap pemangku kepentingan, kemudian skor diplotkan ke dalam sebuah matriks berdasarkan tingkat pengaruh dan setiap kepentingan para pemangku. Matriks tersebut membentuk empat kuadran yaitu kuadran I (subject), kuadran II (players), kuadran III (crowd), dan kuadran IV (context setters) (Bryson, 2004). Matriks tersebut disajikan pada Gambar 1.

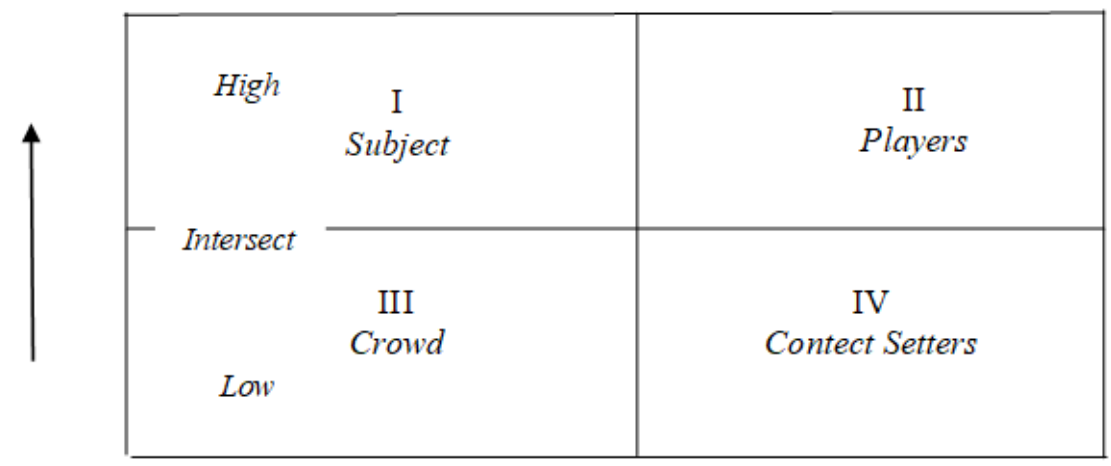

Gambar 1. Matriks analisis pemangku kepentingan 


\section{HASIL DAN PEMBAHASAN}

\section{Kondisi Hasil Tangkapan di TNKJ}

Aktivitas penangkapan ikan di Taman Nasional Karimunjawa (TNKJ) dibatasi hanya boleh dilakukan oleh nelayan skala kecil dengan alat tangkap yang sudah biasa digunakan secara turuntemurun di wilayah Karimunjawa, misalnya panah (speargun), pancing, bubu, dan jaring (Yuliana, 2016). Peraturan tersebut ditetapkan oleh Balai Taman Nasional Karimunjawa (BTNKJ) untuk melindungi keanekaragaman hayati terumbu karang dan SDI.

Pada tahun 2014-2015 terjadi penurunan hasil tangkapan, kemudian pada tahun 2016 terjadi peningkatan kembali (Tabel 2). Fluktuasi hasil tangkapan tersebut utamanya dipengaruhi oleh faktor cuaca dan ketersediaan SDI.

Tabel 2. Kondisi Hasil Tangkapan di Perairan Karimunjawa

\begin{tabular}{|c|c|c|c|c|}
\hline Tahun & Jenis Alat Tangkap & $\begin{array}{l}\text { Jumlah Kapal } \\
\text { yang Mendarat }\end{array}$ & Jumlah Trip & $\begin{array}{l}\text { Jumlah Hasil } \\
\text { Tangkapan Ikan } \\
\text { Karang (kg) }\end{array}$ \\
\hline \multirow[t]{7}{*}{2014} & Pancing tonda & 3.149 & 3.149 & 0 \\
\hline & Pancing ulur & 3.409 & 2.049 & 30.543 \\
\hline & Perangkap lainnya (panah) & 3.409 & 3.801 & 113.000 \\
\hline & Bubu & 1.412 & 1.412 & 18.059 \\
\hline & Jaring insang tetap & 535 & 535 & 5.000 \\
\hline & Bagan perahu/rakit & 861 & 861 & 0 \\
\hline & Total & 12.484 & 11.807 & 166.602 \\
\hline \multirow[t]{7}{*}{2015} & Pancing tonda & 588 & 588 & 0 \\
\hline & Pancing ulur & 904 & 904 & 21.271 \\
\hline & Perangkap lainnya (panah) & 1.441 & 1.441 & 108.736 \\
\hline & Bubu & 524 & 524 & 16.656 \\
\hline & Jaring insang tetap & 300 & 300 & 1.538 \\
\hline & Bagan perahu/rakit & 332 & 332 & 0 \\
\hline & Total & 4.089 & 4.089 & 148.201 \\
\hline \multirow[t]{8}{*}{2016} & Pancing tonda & 596 & 596 & 0 \\
\hline & Pancing ulur & 551 & 551 & 45.466 \\
\hline & Bubu & 358 & 358 & 42.309 \\
\hline & Perangkap lainnya (panah) & 628 & 628 & 121.088 \\
\hline & Jumlah & 628 & 532 & 0 \\
\hline & Pancing lainnya & 306 & 306 & 18.922 \\
\hline & Jaring insang hanyut & 82 & 82 & 600 \\
\hline & Total & 3.657 & 3.561 & 228.385 \\
\hline
\end{tabular}

Sumber: PPP Karimunjawa (2017)

Penurunan hasil tangkapan di tahun 2015 diduga karena adanya penurunan kelimpahan SDI akibat eksploitasi yang berlebihan. Tingkat eksploitasi beberapa jenis ikan karang sudah melampaui batas yang diperbolehkan, di antarnya adalah ikan pisang-pisang (Caesio caerulaurea) mempunyai nilai laju eksploitasi 0,55 ; sunu macan (Plectropomus oligocanthus) mempunyai nilai laju eksploitasi 0,77 (Yuliana, Boer, Fahrudin, Kamal, Pardede, 2016). Padahal batas maksimal nilai laju eksploitasi adalah 0,5 (Pauly, 1984); lebih dari itu berarti sudah berstatus eksploitasi berlebih (over exploited). 


\section{Laju Eksploitasi}

Penghitungan laju eskploitasi didasarkan pada panjang ikan yang tertangkap. Panjang ratarata ikan pisang-pisang yang tertangkap menurun dari Juni-Agustus, sedangkan panjang ikan ekor kuning berfluktuatif (Tabel 3). Ikan pisang-pisang dan ekor kuning merupakan ikan yang hidup pada terumbu karang dengan kedalaman 0-50 m, dan merupakan kelompok ikan mayor dengan jenis makanan termasuk plankton feeder atau pemakan plankton (Kuiter \& Tonozuka, 2004).

Tabel 3. Kelompuk Ukuran Ikan Karang yang Ditangkap dengan Panah

\begin{tabular}{lrrrr}
\hline Waktu Sampling & \multicolumn{2}{c}{ Ekor kuning } & \multicolumn{2}{c}{ Pisang-pisang } \\
\cline { 2 - 5 } & $\begin{array}{r}\text { Jumlah sampel } \\
\text { (ekor) }\end{array}$ & $\begin{array}{r}\text { Panjang rata- } \\
\text { rata } \mathbf{( c m} \text { ) }\end{array}$ & $\begin{array}{r}\text { Jumlah sampel } \\
\text { (ekor) }\end{array}$ & $\begin{array}{r}\text { Panjang rata- } \\
\text { rata (cm) }\end{array}$ \\
\hline Juni & 101 & 22,37 & 101 & 23,67 \\
Juli & 89 & 22,91 & 91 & 23,12 \\
Agustus & 100 & 22,67 & 58 & 22,07 \\
September & 128 & 23,16 & 92 & 23,18 \\
\hline Total & $\mathbf{5 1 7}$ & $\mathbf{-}$ & $\mathbf{3 8 2}$ & - \\
\hline
\end{tabular}

Pendugaan parameter populasi dan penghitungan laju eksploitasi (Tabel 4) menunjukkan bahwa ikan pisang-pisang (Caesio caerulaurea) pertama kali tertangkap pada ukuran $23,78 \mathrm{~cm}$ dan dugaan panjang pertama kali tertangkap berdasarkan persamaan Froese \& Binohlan (2000) adalah $19,09 \mathrm{~cm}$. Hal ini menunjukkan bahwa ikan pisang-pisang tertangkap setelah mencapai panjang pertama kali matang gonadnya. Namun mempunyai nilai laju eksploitasi tinggi yaitu 0,61. Hal yang sama terjadi pada kondisi ikan ekor kuning (C. cuning), yaitu memiliki nilai laju eksploitasi 0,69 . Ikan ekor kuning pertama kali tertangkap $\left(L_{c}\right)$ pada ukuran $21,43 \mathrm{~cm}$ yang panjangnya diduga sama dengan ukuran ikan pertama kali matang gonad $\left(\mathrm{L}_{\mathrm{m}}\right)$ sebesar 21,33 $\mathrm{cm}$. Penangkapan ikan pada kondisi matang gonad dapat mengakibatkan terjadinya overfishing atau tangkap lebih.

Tabel 4. Parameter Populasi, Laju Eksploitasi, dan SPR

\begin{tabular}{|c|c|c|c|c|c|c|c|c|c|c|c|c|}
\hline \multirow[b]{2}{*}{ Spesies } & \multicolumn{4}{|c|}{ Parameter Pertumbuhan } & \multicolumn{4}{|c|}{ Mortalitas } & \multirow[b]{2}{*}{$\underbrace{\bar{E}}_{\bar{E}}$} & \multirow[b]{2}{*}{$\frac{\widehat{\bar{E}}}{\frac{\dot{0}}{\partial}}$} & \multirow[b]{2}{*}{$\underset{\stackrel{E}{\tilde{U}}}{\widehat{U}}$} & \multirow[b]{2}{*}{$\frac{\alpha}{a}$} \\
\hline & $\frac{\overline{\mathrm{E}}}{8}$ & $\times \frac{\bar{E}}{\frac{\pi}{5}}$ & 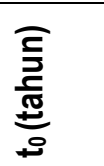 & 遂焉 & $\sum \underset{\underline{\underline{\underline{E}}}}{\underline{\underline{E}}}$ & 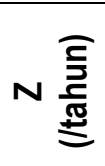 & 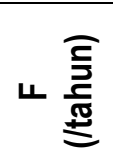 & س & & & & \\
\hline $\begin{array}{l}\text { Caesio } \\
\text { caerulaurea }\end{array}$ & 32,6 & 0,3 & $-0,49$ & 9,0 & 0,47 & 1,2 & 0,7 & 0,61 & 19,1 & 20,1 & 23,8 & 0,25 \\
\hline $\begin{array}{l}\text { Caesio } \\
\text { cuning }\end{array}$ & 36,9 & 0,3 & $-0,52$ & 10,0 & 0,42 & 1,4 & 0,9 & 0,69 & 21,3 & 22,9 & 21,4 & 0,14 \\
\hline
\end{tabular}

\section{Spawning Potential Ratio (SPR)}

Nilai SPR untuk ikan pisang-pisang (C. Caerulaurea) dan ekor kuning (C. cuning) masingmasing adalah 0,25 dan 0,14 (Tabel 4). Kondisi SPR di bawah 0,30 (30\%) menunjukkan bahwa kapasitas ikan dewasa yang siap memijah di alam sangat sedikit. Hal ini dikarenakan banyaknya ikan kecil yang sudah tertangkap sebelum melakukan pemijahan minimum satu kali. 
Hubungan antara potensi pemijahan dan umur spesies ikan menunjukkan ketidakpastian lifehistory yang dapat menyebabkan stok perikanan runtuh atau habis (Nugroho, Patria, Supriatna, \& Adrianto, 2017). Untuk menghindari runtuhnya stok ikan dapat dilakukan dengan meningkatkan ukuran pertama kali ikan tertangkap $\left(\mathrm{L}_{c}\right)$ sehingga nilai SPR akan meningkat juga. Meningkatkan nilai SPR diharapkan dapat meningkatkan sedian stok ikan di alam. Indikasi biologis penurunan stok ikan harus menjadi salah satu perhatian utama pengelolaan perikanan di daerah pesisir. Selain itu, konservasi dan pemanfaatan berkelanjutan sumber daya perikanan adalah dua tujuan utama untuk mempertahankan keberlanjutan perikanan karang.

Perbaikan nilai SPR dapat dilakukan dengan tidak menangkap ikan terlalu kecil dan ikan bertelur atau sedang memijah. Secara teoretis, sejumlah besar ikan akan diselamatkan dengan meningkatkan ukuran rata-rata pertama tertangkap. Melakukan pengaturan ukuran penangkapan (size limit) akan meningkatkan nilai SPR (Nugroho, et al. 2017). Selain itu tidak menangkap ikan matang gonad dapat meningkatkan probabilitas kelangsungan hidup dan dapat mengurangi angka kematian.

\section{Kualitas Air}

Hasil pengukuran kualitas air disajikan pada Tabel 5. Pengukuran kualitas air ini bertujuan untuk menganalisis kesesuaian kualitas air di TNKJ dengan baku mutu perairan laut untuk kehidupan biota. Pengukuran tersebut perlu dilakukan mengingat TNKJ saat ini merupakan salah satu destinasi wisata yang menarik banyak wisatawan. Dikhawatirkan terjadi peningkatan pencemaran di perairan TNKJ.

Tabel 5. Data Kualitas Air TNKJ

\begin{tabular}{lcccccc}
\hline Parameter & Ulangan & Lokasi 1 & Lokasi 2 & Lokasi 3 & Lokasi 4 & Lokasi 5 \\
\hline $\mathrm{pH}$ & 1 & 8,9 & 8,7 & 8,7 & 8,5 & 8,6 \\
& 2 & 8,8 & 8,7 & 8,6 & 8,6 & 8,6 \\
TDS (ppm) & 1 & $2.615,0$ & $2.663,0$ & $2.780,0$ & $2.748,0$ & $2.726,0$ \\
& 2 & $2.615,0$ & $2.663,0$ & $2.760,0$ & $2.748,0$ & $2.726,0$ \\
Suhu $\left({ }^{\circ} \mathrm{C}\right)$ & 1 & 30,7 & 29,8 & 28,9 & 28,9 & 28,7 \\
& 2 & 30,7 & 29,8 & 28,9 & 28,9 & 28,0 \\
BOD (mg/L) & 1 & 1,1 & 0,8 & $<0,79$ & $<0,79$ & 0,8 \\
& 2 & 1,1 & 0,8 & $<0,79$ & $<0,79$ & 0,8 \\
COD (mg/L) & 1 & 68,2 & 85,8 & 67,8 & 65,2 & 67,8 \\
& 2 & 68,2 & 85,9 & 67,7 & 65,1 & 67,8 \\
TSS (mg/L) & 1 & $<8$ & $<8$ & $<8$ & $<8$ & $<8$ \\
& 2 & $<8$ & $<8$ & $<8$ & $<8$ & $<8$ \\
Salinitas (\%o) & 1 & 33,0 & 33,0 & 33,0 & 33,0 & 33,0 \\
& 2 & 33,0 & 33,0 & 33,0 & 33,0 & 33,0 \\
\hline
\end{tabular}

Data kualitas air pada Tabel 5 sesuai dengan baku mutu perairan yang ditetapkan dengan Keputusan Menteri Negara Lingkungan Hidup No. 51 Tahun 2004 tentang Baku Mutu Air Laut untuk Biota Laut. Salinitas air laut di lokasi penelitian adalah 33,0\%, sesuai dengan baku mutu 33-34\%o; pH juga sesuai dengan baku mutu. Parameter kualitas air lainnya berada di bawah nilai baku mutu. Hal tersebut menunjukkan bahwa perairan TNKJ masih layak untuk kehidupan biota laut, tidak tercemar oleh kegiatan manusia di daratan. Kondisi ini menguntungkan bagi kehidupan terumbu karang yang 
merupakan habitat utama bagi ikan karang. Terumbu karang sangat sensitif terhadap limbah berupa padatan (terlarut atau suspensi) karena akan menghambat penetrasi sinar matahari yaang sangat diperlukan oleh kehidupan terumbu karang.

\section{Analisis Stakeholder}

Keberlanjutan SDI karang tidak dapat terlepas dari aspek pengelolaan. Pihak yang bertanggungjawab terhadap pengelolaan ikan karang adalah BTNKJ sebagai otoritas pengelola. Namun, pengelolaan ikan karang tidak semata-mata merupakan BTNKJ saja. Masyarakat dan stakeholder juga harus terlibat aktif dalam pengelolaan. Untuk menentukan prioritas keterlibatan dalam pengelolaan ikan karang dilakukan analisis stakeholder. Analisis stakeholder diperlukan untuk mengetahui pihak-pihak yang terlibat dan berpengaruh dalam pengelolaan perikanan karang. Hasil analisis stakeholder disajikan pada Tabel 6. Dari hasil analisis stakeholder tersebut, pengelola (dalam hal ini BTNKJ) dapat melakukan langkah-langkah taktis dan strategis dalam mengelola ikan karang dengan melibatkan stakeholder utama.

Tabel 6. Analisis Stakeholder dalam Pengelolaan Perikanan Karang

\begin{tabular}{cllcc}
\hline \multirow{2}{*}{ Kode. } & \multicolumn{1}{c}{ Stakeholder } & \multirow{2}{*}{ Kategori } & \multicolumn{2}{c}{ Kriteria Evaluasi } \\
\cline { 3 - 5 } & & Kepentingan & Pengaruh \\
\hline a & BTNKJ & Primer & 1 & 5 \\
b & PPP Karimunjawa & Primer & 1 & 4 \\
c & Dinas Perikanan Kabupaten Jepara & Primer & 1 & 1 \\
d & Dinas Pariwisata Kabupaten Jepara & Tersier & 2 & 5 \\
e & Lembaga Konservasi Internasional (Rare) & Sekunder & 5 \\
f & The Wildlife Conservation Society (WCS) & Sekunder & 2 & 3 \\
g & Kelurahan & Sekunder & 3 & 3 \\
h & Kecamatan & Sekunder & 3 & 4 \\
i & Pokmaswas & Primer & 3 & 4 \\
j & Masyarakat Mitra Polhut & Primer & 3 & 2 \\
k & Nelayan & Primer & 5 & 2 \\
I & Pengepul ikan & Sekunder & 4 & 2 \\
m & Pedagang ikan & Sekunder & 4 & 1 \\
n & Wisatawan & Tersier & 3 & 1 \\
o & Pemandu wisata & Tersier & 2 & 2 \\
p & Perusahaan kapal penyeberangan & Tersier & 1 & 2 \\
q & Agen wisata & Tersier & 1 & 2 \\
r & Pemilik homestay/hotel & Tersier & 2 & 2 \\
s & Pemilik perahu wisata & Tersier & 2 & 2 \\
t & Penyedia alat selam dan snorkeling & Tersier & 2 & \\
u & Pedagang makanan & Tersier & 1 & \\
\hline & & & & 2 \\
\hline
\end{tabular}

Stakeholder (pemangku kepentingan) dalam pengelolaan perikanan karang di TNKJ yang teridentifikasi ada 21 pihak (Tabel 6). Para pemangku kepentingan tersebut memiliki peran dan tanggung jawab masing-masing dalam pengelolaan perikanan karang. Hasil analisis pemangku kepentingan diplotkan dalam matriks (Gambar 2). Dari matriks tersebut dapat diketahui pihak-pihak yang memegang peranan penting dalam pengelolaan perikanan karang di TNKJ. 


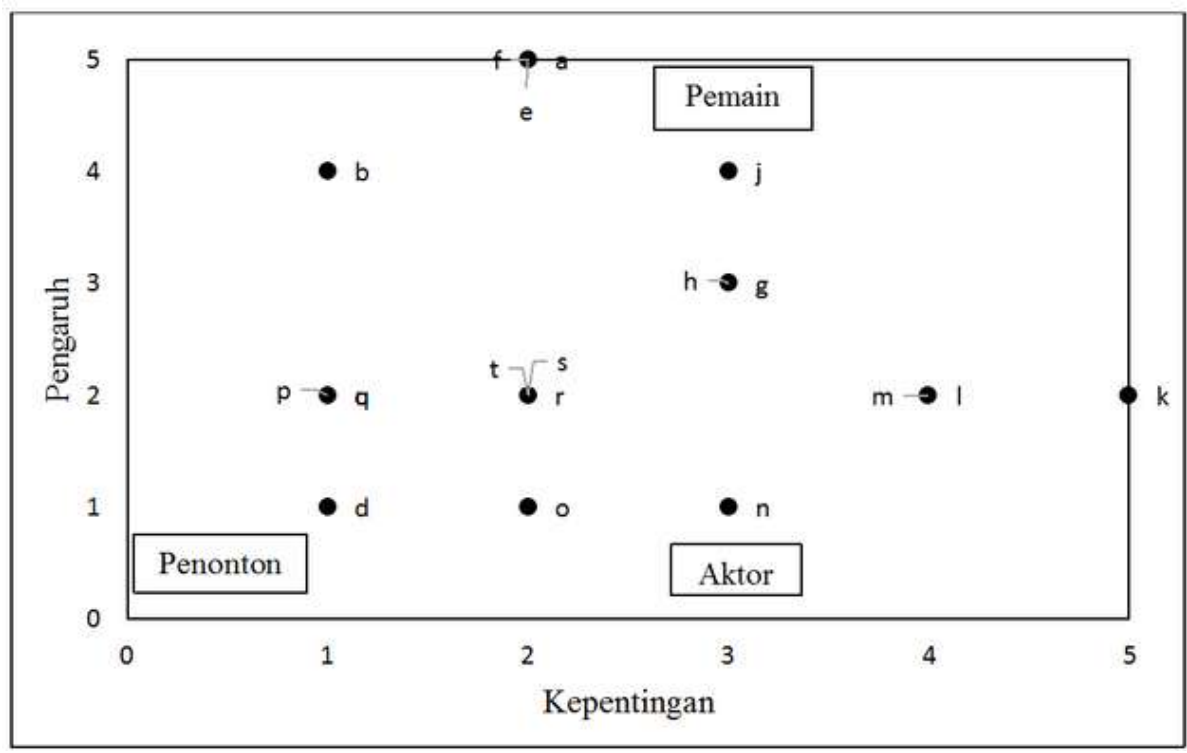

Gambar 2. Matriks analisis stakeholder (pemangku kepentingan)

(Keterangan: $a=$ BTNKJ; $b=P P P$ Karimunjawa; c=Dinas Perikanan, Dinas Pariwisata; e=RARE; $f=W C S$; $\mathrm{g}=$ Kelurahan; h=Kecamatan; i=Pokmaswas; $\mathrm{j}=$ Masyarakat Mitra Polhut; k=Nelayan; l=Pengepul ikan; $\mathrm{m}=$ pedagang ikan; $\mathrm{n}=$ wisatawan; $\mathrm{o=pemandu}$ wisata; $\mathrm{p}=$ perusahaan kapal; $\mathrm{q}=$ agen wisata; $r=$ pemilik penginapan; s=pemilik perahu wisata; $t=$ penyedia alat selam; $u=p e d a g a n g ~ m a k a n a n)$

Pada Gambar 2 dapat dilihat bahwa ada pihak-pihak yang berada pada Kuadran Subjek. Pihak-pihak inilah yang memegang kunci dalam pengelolaan perikanan karang di TNKJ. Ada empat pihak yang berada di kuadran tersebut, dan semuanya adalah pemegang otoritas pengelolaan perikanan dan Lembaga Swadaya Masyarakat (LSM) sebagai partner kerja otoritas pengelola. Kempat pemangku kepentingan tersebut mempunyai nilai pengaruh yang paling tinggi yaitu 5. Menurut Bryson (2004), pemangku kepentingan yang berada pada kuadran I (Subjek) adalah pihakpihak yang mempunyai kewenangan dalam pengelolaan. Oleh karena itu, keempat pihak itulah yang diharapkan dapat mendorong adanya kebijakan pengelolaan ikan karang sekaligus mendorong implementasinya oleh pemangku kepentingan yang ada di Kuadran IV (Aktor) yang terdiri atas nelayan, pengepul ikan, pedagang ikan, dan wisatawan. Keempat pemangku kepentingan yang berada di Kuadran IV, menurut Bryson (2004) mempunyai nilai kepentingan yang tinggi terhadap ikan karang dan mempunyai nilai pengaruh yang rendah.

\section{SIMPULAN}

Famili ikan Caesionidae (Caesio cuning dan C. caerlaurea) mempunyai nilai laju eksploitasi (E) $>0,5$ tepatnya 0,69 dan 0,61, berada dalam kondisi over exploited. Diperlukan upaya pengelolaan untuk mengendalikan stok kedua jenis ikan tersebut di alam. Hasil analisis SPR menunjukkan bahwa kedua jenis ikan mempunyai nilai $\operatorname{SPR}<0,3$, yaitu 0,14 dan 0,25, artinya kedua jenis ikan tersebut berada pada kondisi over exploited.

Parameter kualitas air lainnya berada di bawah nilai baku mutu. Hal tersebut menunjukkan bahwa perairan TNKJ masih layak untuk kehidupan biota laut, tidak tercemar oleh kegiatan manusia 
di daratan. Kondisi ini menguntungkan bagi kehidupan terumbu karang yang merupakan habitat utama bagi ikan karang.

Hasil analisis stakeholder menunjukkan bahwa pihak-pihak pemerintah memegang pengaruh yang kuat, di antaranya adalah BTNKJ, PPP Karimunjawa, Lembaga Swadaya Masyarakat (Rare, dan WCS). Sementara nelayan hanya menjadi aktor tetapi tidak berpengaruh kuat terhadap pengelolaan perikanan karang.

\section{REFERENSI}

Ault, J., Smith, S.G., Monaco, M.E., Appeldoorn, R.S. (2008). Length-based aassessment of sustainability benchmarks for coral reef fishes in Puerto Rico. Environmental Conservation 35 (3):22-23.

Blackhart, K., Stanton, D.G., Shimada, A.M. (2006). NOAA fisheries glossary. NOAA technical memorandum NMFS-F/SPO-69. Maryland: National Oceanic and Atmospheric Administration. Silver Spring.

Bryson JM. (2004). What to do when stakeholdes matter: Stakeholder identification and analysis techniques. Public Management Review/online, 8: 21-53.

BTNKJ (Balai Taman Nasional Karimunjawa). (2014). Statistik balai taman nasional Karimunjawa 2013. Semarang: BTNKJ.

Campbell SJ, Kartawijaya T, Yulianto I, Prasetia R, Clifton J. (2013). Co-management approaches and incentives improve management effectiveness in the Karimunjawa National Park, Indonesia. Marine Policy, 41:72-79.

Carruthers TR, Walters CJ, McAllister MK. (2012). Evaluating methods that classify fisheries stock status using only fisheries catch data. Fisheries Research, 119-120: 66-79.

Charles AT. (2001). Sustainable fishery systems. London: Balckwell Sciences.

Froese, R., Binohlan, C. (2000). Empirical relationships to estimate asymptotic length, length at first maturity and length at maximum yield per recruit in fishes, with a simple method to evaluate length frequency data. Journal of Fish Biology, 56:758-773.

Gayanilo Jr FC, Sparre P, Pauly D. (2005). FAO-ICLARM stock assessment tools (FiSAT II). Revised version. User's manual. Food and Agriculture Organization of the United Nations, Rome. http://www.fao.org/docrep/009/y5997e/y5997e00.htm (Diakses 12-1-2017).

Grimble R, Chan M, Aglionby J, \& Quan J. (1995). Trees and trade-offs: A stakeholder to natural resource management. Gatekeeper series, No. SA52.

Kuiter, H.R., Tonozuka, T. (2004). Pictorial guide to Indonesia reef fisheries part I, II, III. Bali Indonesia. PT. Dive \& Dive's.

Nugroho, D., Patria, M.P., Supriatna, J., Adrianto, L. (2017). The estimates spawning potential ratio of three dominant demersal fish species landed in Tegal, north coast of Central Java, Indonesia. Biodiversitas, 18 (2): 844-849.

Ongkers, OTS. (2006). Pemantauan terhadap parameter populasi ikan teri merah (Encrasicholina heteroloba) di Teluk Ambon Bagian Dalam. Prosiding Seminar Nasional Ikan IV tanggal 2930 Agustus 2006. Jatiluhur: Masyarakat Iktiologi Indonesia kerjasama dengan Loka Riset Pemacuan.

Pauly, D. (1984). Some simple methods for tropical fish stock. FAO Fish. Tech. Pap. (243): 52 pp. French and Spanish.

PPP (Pelabuhan Perikanan Pantai) Karimunjawa. (2014). Laporan tahunan pelabuhan perikanan pantai Karimunjawa tahun 2014. Karimunjawa: PPP Karimunjawa. 
PPP (Pelabuhan Perikanan Pantai) Karimunjawa. (2017). Data perikanan Karimunjawa. [Tidak Dipublikasikan].

Sadovy de Mitcheson Y, Cornish A, Domeier M, Colin PL, Russell M, Lindeman KC. (2008). A global baseline for spawning aggregations of reef fishes. Conservation Biology, 22: 1233-1244.

Yuliana, E. (2016). Pengelolaan perikanan karang dengan pendekatan ekosistem di kawasan konservasi (Kasus: Taman Nasional Karimunjawa). Disertasi. Bogor: Institut Pertanian Bogor.

Yuliana, E., Boer, M., Fahrudin A., Kamal, M.M., Muttaqin E. (2016). Status stok ikan karang target di kawasan konservasi Taman Nasional Karimunjawa. Jurnal Penelitian Perikanan Indonesia, 22 (1): 9-16. 